\title{
Características morfogênicas do capim-mombaça (Panicum maximum Jacq. cv. Mombaça) adubado com fontes de fósforo, sob pastejo ${ }^{1}$
}

\section{Ulysses Cecato ${ }^{2}$, Viviane Deczka Skrobot ${ }^{3}$, Glauber Marcelo Fakir ${ }^{4}$, Clóves Cabreira Jobim²,

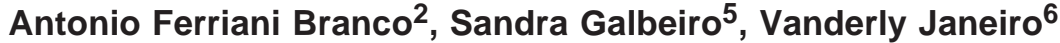

${ }^{1}$ Financiado pela Ferilizantes Mitsui LTDA.

2 Departamento de Zootecnia da UEM, Av. Colombo, 5790 - CEP: 87020-900, Maringá - PR. Pesquisador do CNPq.

${ }^{3}$ Mestre em Produção Animal pelo PPZ/DZO-UEM.

4 Zootecnista formado pela UEM.

${ }^{5}$ Doutoranda do PPZ/DZO-UEM.

${ }^{6}$ Departamento de Estatística da UEM - Doutorando na USP-SP.

RESUMO - O experimento foi realizado no período de dezembro de 2002 a abril de 2003, com o objetivo de avaliar, em capim-mombaça, o efeito de duas fontes de fósforo (superfosfato simples + superfosfato triplo e termofosfato magnesiano Yoorin ${ }^{\circledR}$ ), em função dos dias (24) e da época de avaliação (verão e outono), sobre intervalo (IAPF) e taxas de aparecimento (TAPF), alongamento (TALF) e total de folhas senescentes (TFS), altura da primeira (HPLIG) e da última lígula (HULIG) e número de folhas expandidas (NFEX), em expansão (NFE), total de folhas (NTF) e total de folhas vivas (NTFV). O delineamento experimental utilizado foi em blocos ao acaso com três repetições. Entre as variáveis avaliadas, somente a taxa de alongamento foliar foi maior para os perfilhos adubados com o SFS+SFT. Diferenças foram encontradas para a época de avaliação, em que o verão apresentou maiores TALF, HPLIG e HULIG. Os dias de avaliação realizados nos períodos do verão e outono apresentaram efeito para HPLIG, NFEX e NFE, NTF, NTFV, TFS. Para a interação dias $\times$ época, somente para o NTFV e TFS houve correlações lineares positivas. As fontes de fósforo não influenciaram a morfogênese do capim-mombaça, exceto o alongamento foliar, no qual o tratamento SFS+SFT - fósforo solúvel promoveu maior aumento que Yoorin ${ }^{\circledR}$. No verão, as plantas apresentaram maior crescimento dos perfílhos e de sua taxa de alongamento foliar que no outono.

Palavras-chave: crescimento foliar, perfilhos, período, senescência

\section{Morphogenic characteristics of mombaçagrass (Panicum maximum Jacq.cv. Mombaça) fertilized with phosphorus sources, under grazing}

\begin{abstract}
The experiment was carried out from December/2002 to April/2003 and aimed to evaluate the effects of two phosphorus sources (ordinary superphosphate + triple superphosphate and Yoorinâ magnesium thermophosphate), as a function of days (24) and evaluation period (summer and autumn) on leaf appearance interval (LAPI), leaf elongation rate (LER), leaf senescence (TLS), first and last ligule height (FLH; LLH), number of expanded leaves (NEL), number of leaves in expansion (NLE), total number of leaves (TNL), total number of live leaves (TNLL), and grazing return rate (GRR) on mombaçagrass (Panicum maximum Jacq. cv. Mombaça). The experimental design was randomized blocks with three replications. There was no difference between phosphorus sources in all evaluated variables, except for leaf elongation rate, which was higher in tillers fertilized with the SPS+TSP treatment. Differences were found between evaluation periods, with summer showing higher leaf elongation rate and ligule height (first and last). The days evaluated indicated effect on first ligule height (FLH; LLH), number of expanded leaves (NEL), number of leaves in expansion (NFE), total number of leaves (TNL), total number of live leaves (TNLL), total number of senescent leaves (TLS), and grazing return rate (GRR). For days and period interactions only TNLL and TSL had positive linear correlations.
\end{abstract}

Key Words: leaf growth, period, senescence, tillers

\section{Introdução}

$\mathrm{Na}$ exploração racional, é relevante que a pastagem apresente persistência e alta produção, para que o animal possa expressar o seu potencial genético com a utilização de forragens de alto valor nutritivo (Peternelli, 2003).

O fósforo está entre os elementos mais importantes para o vigor e desenvolvimento das plantas. O crescimento 
de uma planta não é dependente de um único elemento, mas do nível de cada nutriente essencial (Fonseca et al., 2000). Em razão de o fósforo ser limitante da produção e de os solos brasileiros serem bastante deficientes, infere-se que a prática de adubação assume papel fundamental para o estabelecimento e a manutenção das pastagens.

É imprescindível o aprimoramento de técnicas para aumentar a utilização deste nutriente, sem, contudo, elevar os custos de produção. A possibilidade do emprego de fosfatos naturais a baixo custo de produção tem sido enfatizada como alternativa viável para o suprimento da necessidade de fósforo nos solos brasileiros. No entanto, os fosfatos naturais têm demonstrado baixa eficiência inicial, em relação às fontes solúveis em água, melhorando com o passar dos anos (Franco, 2003).

A descrição do pasto em condição vegetativa, segundo Lemaire (1997), pode ser definida pela caracterização e combinação das variáveis morfogênicas, em que a taxa de aparecimento foliar, a taxa de alongamento foliar e a duração da vida das folhas são as três características mais importantes.

A dinâmica de crescimento e morte das plantas pode ser medida em nível de perfilho individual, usando a técnica de perfilhos marcados (Lemaire \& Agnusdei, 1999; Pontes, 2000).

Almeida et al. (1997) relataram que a técnica de utilização de perfilhos marcados é uma alternativa viável e confiável para determinar a taxa de crescimento da pastagem em experimentos de pastejo, além de fornecer informações sobre o comportamento das variáveis morfogênicas, como taxa de aparecimento foliar, duração de vida das folhas, taxa de senescência, entre outras. Esses autores atribuíram esta resposta positiva da taxa de acúmulo de folhas verdes ao aumento na oferta de forragem do capimelefante anão, por maior taxa de expansão foliar, uma vez que a taxa de surgimento de folhas não foi afetada.

A taxa de aparecimento foliar, geralmente expressa em número de folha.perfilho ${ }^{-1}$ dia $^{-1}$, é uma variável morfogênica que mede a dinâmica do fluxo de biomassa das plantas. $\mathrm{O}$ filocrono, termo utilizado para descrever o intervalo de aparecimento foliar, é relativamente constante para determinado genótipo durante o desenvolvimento vegetativo de um perfilho, quando em condições ambientais constantes. No entanto, Gomide \& Gomide (1997) discutem que a taxa de aparecimento foliar está em função do genótipo, do nível de inserção, dos fatores do meio, da estação do ano, da intensidade e freqüência de desfolhação e dos nutrientes minerais.

Grant et al. (1981) mencionam que a taxa de aparecimento foliar é largamente influenciada pela taxa de alonga- mento foliar e pelo comprimento do cartucho da bainha (pseudocolmo), o qual determina a distância percorrida pela folha para emergir.

A duração de vida das folhas, fator determinante do crescimento e da produção de biomassa das plantas (Lemaire, 1997), determina o número máximo de folhas vivas por perfilho. Segundo Nabinger (1996), esta variável morfogênica é o determinante do equilíbrio entre o crescimento e a senescência.

Em condição vegetativa, a combinação destas características morfogênicas, segundo Chapman \& Lemaire (1993), resulta nas características estruturais do relvado, que determinam a área foliar.

O objetivo neste trabalho foi avaliar diferentes fontes de fósforo sobre as características morfogênicas do capimmombaça (Panicum maximum Jacq. cv. Mombaça).

\section{Material e Métodos}

O experimento foi realizado no município de Nova Esperança-PR, no período de dezembro de 2002 a abril de 2003.

O clima é classificado como subtropical úmido mesotérmico com verões quentes, geadas pouco freqüentes e tendências de concentração de chuvas nos meses de verão (Cfa) (Corrêa, 1996). As coordenadas geográficas são $23^{\circ} 25^{\prime}$ de latitude, $51^{\circ} 55^{\prime}$ e longitude e, aproximadamente, $500 \mathrm{~m}$ de altitude (Tabela 1 ).

O solo da área experimental, originado do Arenito Caiuá, é classificado como Latossolo Amarelo Distrófico, (EMBRAPA, 1999), apresentando $88 \%$ de areia, $2 \%$ de silte e $10 \%$ de argila e a seguinte composição química: $\mathrm{pH} \mathrm{em} \mathrm{CaCl}_{2}=5,2 ; \mathrm{pH}$ em $\mathrm{H}_{2} \mathrm{O}=5,85 ; \mathrm{Al}^{+++}=0,06$; $\mathrm{H}^{++} \mathrm{Al}^{+++}=2,77 ; \mathrm{Ca}^{+++} \mathrm{Mg}^{++}=2,99 ; \mathrm{Ca}^{++}=1,95 ;$ $\mathrm{K}^{+}=0,16 \mathrm{cmolc} / \mathrm{dm}^{-3}$, respectivamente; $\mathrm{P}=14,5\left(\mathrm{mg} / \mathrm{dm}^{-3}\right)$; $\mathrm{C}=6,04\left(\mathrm{~g} / \mathrm{dm}^{-3}\right)$.

Em fevereiro de 2002, foi implantada a pastagem do capim-mombaça (Panicum maximum Jacq. cv. Mombaça), via seminal, utilizando-se $18 \mathrm{~kg}$ de sementes.ha ${ }^{-1}$, com valor cultural de $20 \%$.

A adubação fosfatada foi realizada no dia anterior à implantação da pastagem, incorporando-se ao solo $140 \mathrm{~kg} \cdot \mathrm{ha}^{-1}$ de $\mathrm{P}_{2} \mathrm{O}_{5}$ fornecido por duas fontes: Yoorin ${ }^{\circledR}$ (termofosfato magnesiano Yoorin ${ }^{\circledR}$ ) e formulado de superfosfato simples e superfosfato triplo (SFS+SFT).

A mistura dos adubos fosfatados (superfosfato simples e superfosfato triplo) ocorreu para que houvesse equilíbrio nos teores de enxofre e cálcio, em comparação ao Yoorin ${ }^{\circledR}$. Durante o período experimental, foram aplica- 
Tabela 1 - Temperatura média mínima (mín) e máxima (max.), precipitação, umidade relativa (UR) do ar e insolação de novembro/2002 a maio/2003

Table 1 - Minimum (min.) and maximum (max.) average temperature, rainfall (ppt), relative humidity (RH), and insolation from August/2002 to May/2003

\begin{tabular}{|c|c|c|c|c|c|}
\hline \multirow{3}{*}{$\begin{array}{l}\text { Ano/Mês } \\
\text { Year/Month }\end{array}$} & \multicolumn{2}{|c|}{$\begin{array}{c}\text { Temperatura média }\left({ }^{\circ} \mathrm{C}\right) \\
\text { Average temperature }\end{array}$} & \multirow[t]{3}{*}{$\begin{array}{l}\text { Precipitação (mm) } \\
\quad \text { Rainfall }(\mathrm{mm})\end{array}$} & \multirow[t]{3}{*}{$\begin{array}{l}\text { UR }(\%) \\
\text { RH }\end{array}$} & \multirow[t]{3}{*}{$\begin{array}{c}\text { Insolação } \text { (horas) } \\
\text { Insolation (hours) }\end{array}$} \\
\hline & Mínima & Máxima & & & \\
\hline & Minimum & Maximum & & & \\
\hline \multicolumn{6}{|l|}{2002} \\
\hline Novembro (November) & 19,61 & 30,27 & 186,01 & 71,06 & 206,20 \\
\hline Dezembro (December) & 20,93 & 32,42 & 87,73 & 69,43 & 225,99 \\
\hline \multicolumn{6}{|l|}{2003} \\
\hline Janeiro (January) & 21,56 & 32,58 & 279,62 & 79,94 & 152,52 \\
\hline Fevereiro (February) & 21,65 & 31,62 & 209,16 & 73,39 & 187,32 \\
\hline Março (March) & 20,20 & 29,96 & 151,90 & 71,27 & 256,37 \\
\hline Abril (April) & 18,25 & 28,99 & 143,40 & 68,18 & 221,04 \\
\hline Maio (May) & 14,08 & 25,70 & 50,22 & 66,36 & 253,58 \\
\hline
\end{tabular}

Fonte: Estação Agrometereológica de Paranavaí. Boletim Metereológico - IAPAR, 2002/2003.

Source: Paranavai Agrometeorological Station. 'Boletim Metereológico - IAPAR', 2002/2003.

dos, a lanço, $1.000 \mathrm{~kg} / \mathrm{ha}$ do formulado 15-0-15, correspondendo a 150 de $\mathrm{N}$ e de $\mathrm{K}_{2} \mathrm{O} /$ ha/ano, parcelado em três aplicações.

Após a formação, a área foi dividida em seis piquetes de 0,7 a 1 hectare, reservando-se uma área adjacente $(4,4$ ha $)$ para a permanência dos animais reguladores. Os piquetes foram divididos por cerca elétrica e providos de bebedouros e cochos de sal.

Os tratamentos estudados foram duas fontes de fosfato, Yoorin ${ }^{\circledR}$ e formulado de superfosfato simples e superfosfato triplo (SFS+SFT), e dois períodos de avaliação: verão e outono. Os efeitos dos tratamentos foram avaliados em delineamento experimental de blocos casualizados, com três repetições.

Para o manejo do pasto, usou-se a técnica put-andtake, descrita por Mott \& Lucas (1952), procurando-se manter o pasto com 50 a $60 \mathrm{~cm}$ de altura, utilizando-se novilhos cruzados (europeu x zebu) com peso inicial de, aproximadamente, $240 \mathrm{~kg}$. O ajuste da lotação foi realizado a cada 15 dias. A lotação animal nos meses de janeiro e fevereiro (avaliações do verão) e de março e abril (avaliações do outono), para o tratamento Yoorin ${ }^{\circledR}$, foi de 3,8 e 4,9 e 4,3 e 2,7 e para o SS+SFT, de 3,4 e 4,1 e 4,6 e 2,6 UA/ha respectivamente.

Para as avaliações das características morfogênicas, foram demarcadas quatro transectas por piquete e escolhidos 10 perfilhos ao acaso por transecta, totalizando 40 perfilhos (em plantas diferentes), representativos da altura média da pastagem, marcados com fios coloridos. Duas vezes por semana (terças e sábados), durante 24 dias no verão e 23 dias no outono, os perfilhos foram avaliados e, a partir das coletas dos dados, calculadas as seguintes variáveis médias representativas do período de avaliação, de cada unidade experimental: a) a altura da primeira lígula (HPLIG $-\mathrm{cm})$ : tomada no perfil da planta, tendo como valor a distância da superfície do solo até a altura da lígula da folha verde mais velha que se encontrava no momento da marcação do perfílho; b) altura da última lígula (HULIG $\mathrm{cm}$ ): aferida como a variável anterior, sendo a lígula da folha adulta mais jovem; c) número médio de folhas expandidas (NFEX): somatório das folhas expandidas de cada perfilho; d) número médio de folhas em expansão (NFE): somatório das folhas em expansão de cada perfilho; e) número total de folhas por perfilho (NTF): somatório do número de folhas expandidas (NFEX), número de folhas em expansão (NFE) e total de folhas senescentes (TFS); f) número total médio de folhas vivas por perfilho (NTFV): diferença entre o número total de folhas e o número total de folhas mortas (TFS) de cada perfilho; g) número total de folhas senescentes (TFS): diferença do número total de folhas (NTF) e número total de folhas vivas (NTFV). Considerou-se folha morta aquela com $50 \%$ de senescência; $h$ ) intervalo médio de aparecimento foliar (IAPF - dias.folha ${ }^{-1}$. perfilho $^{-1}$ ): média do intervalo de tempo (dias) para o aparecimento de duas folhas sucessivas em cada perfilho; i) taxa de aparecimento foliar (TAPF - dias.folha ${ }^{-1}$.perfilho ${ }^{-1}$ ): o inverso do IAPF (TAPF = 1/média IAPF); j) taxa média de alongamento foliar (TAIF - cm.perfilho ${ }^{-1} \cdot$ dia $^{-1}$ ): diferença entre o comprimento final e o comprimento inicial das folhas em expansão, dividida pelo número de dias entre as medidas.

Para análise estatística dos dados, procedeu-se à análise de variância (PROC GLM) e comparação entre médias pelo teste Tukey (5\%), utilizando-se o pacote estatístico SAS (1993). O modelo estatístico utilizado foi: 


$$
\begin{gathered}
\mathrm{Yijkl}=\mu+\mathrm{Fi}+\mathrm{Bj}+\mathrm{Eij}+\mathrm{EPk}+(\mathrm{FxEP}) \mathrm{ik}+\delta \mathrm{ijk}+\mathrm{Dl} \\
+(\mathrm{FxD}) \mathrm{il}+(\mathrm{EpxD}) \mathrm{kl}+(\text { FxEPxD }) \mathrm{ikl}+\varepsilon \mathrm{ijkl}
\end{gathered}
$$

em que Yijkl é a observação na unidade experimental ijkl; $\mu$, a constante geral; $\mathrm{Fi}$, o efeito da fonte $\mathrm{i} ; \mathrm{Bj}$, o efeito do bloco j; eij, o erro aleatório associado a cada observação yij; epk, o efeito da época k; fxep); ik, a interação fonte i $\times$ época k; $\delta i j k$, o erro aleatório associado a cada observação yijk; dl, o efeito do dia l; (fxd) il, a interação fonte i $\times$ dia l; (epxd) kl, a interação época $\mathrm{k} \times$ dial; (fxepxd); ikl = a interação fonte $\mathrm{i} \times$ época $\mathrm{k} \times$ dia $\mathrm{l} ; \varepsilon$ ijkl, o erro aleatório associado a cada observação Yijkl.

\section{Resultados e Discussão}

Não houve diferença significativa $(\mathrm{P}>0,05)$ entre as fontes de fósforo utilizadas para todas as variáveis avaliadas (Tabela 2), em decorrência, provavelmente, do teor existente no solo $\left(14,5 \mathrm{mg} \cdot \mathrm{dm}^{-3}\right)$, não permitindo diferenciação entre as fontes utilizadas. Todavia, deve-se destacar que o uso do Yoorin ${ }^{\circledR}$, um fosfato de mais lenta dissolução no solo, poderá proporcionar adubações de manutenção em longo prazo.

A ausência ou a ineficiência do adubo fosfatado pode levar a planta a utilizar o fósforo em solução somente para sua manutenção, ocasionando paralisação de seu desenvolvimento, visto sua importância no crescimento radicular, perfilhamento e na persistência das pastagens (Werner, 1984).

Santos et al. (1999) observaram que os capins tanzânia e mombaça submetidos ao pastejo a cada 28, 38 e 48 dias, ao longo do ano, apresentaram entre 4 e 6 folhas vivas por perfilho e aumento do comprimento foliar com o avanço do intervalo de pastejo.

O alongamento da lâmina foliar cessa com a exposição da lígula, apresentando-se completamente expandida quando a folha é considerada adulta (Langer, 1972), iniciando-se, assim, o processo de senescência, cuja intensidade varia conforme as estações do ano e os fatores ambientais.

A taxa de alongamento foliar (TALF) foi maior $(\mathrm{P}<0,05)$ nas plantas adubadas com a fonte solúvel SFS+SFT (Tabela 3). Certamente, isso ocorreu pelo melhor aproveitamento do fósforo durante o experimento, em decorrência de sua maior solubilidade em relação ao Yoorin ${ }^{\circledR}$. É importante salientar que, além da nutrição mineral, fatores como genótipo, temperatura, fotoperíodo, estação do ano e estresse hídrico influenciam consideravelmente a TALF.

A zona de alongamento é um local ativo de grande demanda por nutrientes (Skinner \& Nelson, 1995). Muitos autores relatam a grande importância do nitrogênio na taxa de alongamento foliar, em razão desta variável ser afetada diretamente pelo nutriente, por meio do aumento do número

Tabela 2 - Valores médios da altura da primeira e última lígula (HPLIG; HULIG), número de folhas expandidas (NFEX), em expansão (NFE), total de folhas (NTF), folhas vivas (NTFV) e folhas senescentes (TFS) do capim-mombaça, com fontes de fósforo

Table 2 - Average values of first and last ligule height (FLH; $L L H)$, number of expanded leaves (NEL), number of leaves in expansion (NLE), total number

\begin{tabular}{|c|c|c|c|c|c|c|c|}
\hline Fonte de fósforo & HPLIG $(\mathrm{cm})$ & HULIG $(\mathrm{cm})$ & NFEX & NFE & NTF & NTFV & TFS \\
\hline Phosphorus source & $F L H(\mathrm{~cm})$ & $L L H(\mathrm{~cm})$ & $N E L$ & $N L E$ & $T N L$ & $T N L L$ & $T S L$ \\
\hline Yoorin ${ }^{\circledR}$ & $21,21 \mathrm{a} *$ & $24,39 \mathrm{a}$ & $3,95 \mathrm{a}$ & $1,50 \mathrm{a}$ & $5,35 \mathrm{a}$ & $4,70 \mathrm{a}$ & $0,75 \mathrm{a}$ \\
\hline $\mathrm{SFS}+\mathrm{SFT}^{1}(S S P+T S P)$ & $20,71 \mathrm{a}$ & $23,46 a$ & $3,82 \mathrm{a}$ & $1,46 \mathrm{a}$ & $5,17 \mathrm{a}$ & $4,57 \mathrm{a}$ & $0,70 \mathrm{a}$ \\
\hline CV $(\%)$ & 17,96 & 15,93 & 21,54 & 3,26 & 18,11 & 28,45 & 56,60 \\
\hline
\end{tabular}
of leaves (TNL), total number of alive leaves (TNLL), and total senescent leaves (TSL) of mombaçagrass as affected by phosphorus sources

${ }^{1}$ SFS+SFT: Superfosfato simples e superfosfato triplo (SSP+TSP: ordinary superphosphate + triple superphosphate)

* Médias seguidas por letras distintas $(P<0,05)$ diferem pelo teste Tukey.

* Means followed by different letters $(P<0.05)$ differ by Tukey test.

Tabela 3 - Valores médios da taxa de alongamento (TALF), intervalo de aparecimento (IAPF) e taxa de aparecimento foliar (TAPF) do capim-mombaça, com fontes de fósforo, sob pastejo

Table 3 - Average values for leaf elongation rate (LelR), leaf appearance interval (Lapl), and leaf appearance rate (LapR) of mombaçagrass with phosphorus

\begin{tabular}{|c|c|c|c|}
\hline $\begin{array}{l}\text { Fonte de fósforo } \\
\text { Phosphorus source }\end{array}$ & $\begin{array}{l}\text { TALF }\left(\mathrm{cm} \cdot \text { dia }^{-1} \cdot \text { perfilho }^{-1}\right) \\
\text { LelR }\left(\mathrm{cm}^{\text {day }} \text { day }^{-1} \cdot \text { tiller }^{-1}\right)\end{array}$ & 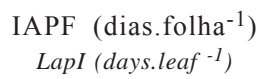 & $\begin{array}{c}\text { TAPF (folhas.dia }{ }^{-1} \cdot \text { perfilho }^{-1} \text { ) } \\
\text { LapR (leaves.day } \text { (tiller }^{-1} \text { ) }\end{array}$ \\
\hline Yoorin ${ }^{\circledR}$ & $1,13 b^{*}$ & $2,85 \mathrm{a}$ & $0,36 \mathrm{a}$ \\
\hline SFS+SFT1 $(S S P+T S P)$ & $1,31 \mathrm{a}$ & $3,48 \mathrm{a}$ & $0,29 a$ \\
\hline CV (\%) & 4,17 & 20,16 & 24,45 \\
\hline
\end{tabular}
sources, under grazing

${ }^{1} \mathrm{SS}+\mathrm{ST}$ : superfosfato simples + superfosfato triplo (SSP+TSP: ordinary superphosphate + triple superphosphate)

* Médias seguidas por letras distintas $(P<0,05)$ diferem pelo teste Tukey.

* Means followed by different letters $(P<0.05)$ differ by Tukey test. 
de células. Porém, a relevância do fósforo em todos os processos morfofisiológicos da planta nem sempre é considerada, ficando em segundo plano. Este elemento é vital, pois constitui o ATP (Adenosinatrifosfato), a maior fonte de energia de um organismo para desempenhar suas funções biológicas.

Grandes variações entre e dentro de cada espécie são atribuídas ao manejo e às condições climáticas. Almeida et al. (1997), em capim-elefante anão, observaram aumento da TAlF de 2 para $3,4 \mathrm{~cm}$. dia ${ }^{-1}$, com o incremento dos níveis de oferta de forragem.

Segundo Zarrough et al. (1984), a TAPF correlaciona-se negativamente à TALF, tendência que pode ser observada neste trabalho (Tabela 3).

Diferenças significativas $(\mathrm{P}<0,01)$ foram encontradas para a época de avaliação; houve maior altura de lígula (HPLIG e HULIG) no verão que no outono (Tabela 4), em decorrência das melhores condições climáticas (Tabela 1), uma vez que, no outono, houve queda de temperatura e diminuição do fotoperíodo e das chuvas, o que pode ter ocasionado menor crescimento dos perfilhos. Conseqüentemente, a planta, fisiologicamente, pode estar em fase de estabilização de crescimento, para priorizar a diferenciação do meristema apical (Langer, 1972), com a emissão das inflorescências em espécies do gênero Panicum.

Nesta pesquisa, a taxa de alongamento foliar (TALF) foi maior $(\mathrm{P}<0,05)$ no verão (Tabela 5).
As avaliações de verão foram realizadas no mês de janeiro, quando foi detectado o maior índice de pluviosidade durante todo o período experimental (Tabela 1). Morales et al. (1997), trabalhando com cornichão, verificaram diminuição de, aproximadamente, $60 \%$ da TALF da haste principal, quando houve redução em 50\% na disponibilidade hídrica. A temperatura também foi elevada, favorecendo maior crescimento dos perfilhos avaliados no verão. Estas respostas ocorrem, provavelmente, porque o capim-mombaça é uma gramínea do tipo $\mathrm{C} 4$, não apresentando o mesmo crescimento do verão no outono-inverno, visto que luz, temperatura e umidade tornam-se desfavoráveis para seu máximo desenvolvimento (Rodrigues \& Rodrigues, 1987).

Os valores encontrados para a TAPF referentes às duas épocas (verão e outono) e às duas fontes de fósforo (Yoorin ${ }^{\circledR}$ e SFS + SFT) foram superiores aos encontrados por Barbosa et al. (1996), que obtiveram as maiores taxas de aparecimento e expansão de folhas de cultivares de Panicum maximum no verão e as menores no inverno, enquanto a senescência foi elevada no inverno e na primavera.

A HPLIG apresentou aumento quadrático $(\mathrm{P}<0,05)$, em função dos dias de avaliação (Figura 1), demonstrando que, mesmo no pastejo contínuo, tanto no verão como no outono os perfilhos crescem, mas cessam seu crescimento em determinada altura para o desenvolvimento de novos órgãos ou novos perfilhos. Fatores como clima, precipitação, tempera-

Tabela 4 - Valores médios da primeira e última lígulas (HPLIG; HULIG), número de folhas expandidas (NFEX), em expansão (NFE), total de folhas (NTF), total de folhas vivas (NTFV), folhas senescentes (TFS) do capim-mombaça, em duas épocas de avaliação

Table 4 - $\quad$ Average values for first and last ligule height (FLH; LLH), number of expanded leaves (NEL), number of leaves in expansion (NLE), total number of leaves (TNL), total number of live leaves (TNLL), and total senescent leaves (TSL) of mombaçagrass in growth periods

\begin{tabular}{|c|c|c|c|c|c|c|c|}
\hline Época & HPLIG $(\mathrm{cm})$ & HULIG $(\mathrm{cm})$ & NFEX & NFE & NTF & NTFV & TFS \\
\hline Season & FLH & $L L H$ & $N E L$ & $N L E$ & $T N L$ & $T N L L$ & $T S L$ \\
\hline Verão (Summer) & $24,57 \mathrm{a}$ & $28,57 a^{*}$ & $3,89 \mathrm{a}$ & $1,55 \mathrm{a}$ & $5,34 \mathrm{a}$ & $4,64 \mathrm{a}$ & $0,82 \mathrm{a}$ \\
\hline CV (\%) & 25,54 & 42,04 & 5,71 & 37,06 & 15,02 & 13,93 & 55,57 \\
\hline
\end{tabular}

* Médias seguidas por letras distintas $(P<0,05)$ diferem pelo teste Tukey

* Means followed by different letters $(P<0.05)$ differ by Tukey test.

Tabela 5 - Valores médios da taxa de alongamento (TALF), intervalo de aparecimento (IAPF) e taxa de aparecimento foliar (TAPF) do capim-mombaça, em duas épocas de avaliação

Table 5 - Average values for leaf elongation rate (LER), leaf appearance interval (LAPI) and leaf appearance rate (LAPR) of mombaçagrass in two growth periods

\begin{tabular}{|c|c|c|c|}
\hline $\begin{array}{l}\text { Época } \\
\text { Season }\end{array}$ & $\begin{array}{l}\text { TALF }\left(\mathrm{cm} \cdot \text { dia }^{-1} \cdot \text { perfilho }^{-1}\right) \\
\text { LelR }\left(\mathrm{cm}^{\text {day }} \text { day }^{-1} \cdot \text { tiller }^{-1}\right)\end{array}$ & $\begin{array}{l}\text { IAPF }\left(\text { dias.folha }{ }^{-1}\right) \\
\left.\text { LapI (days.leaf }{ }^{-1}\right)\end{array}$ & $\begin{array}{c}\text { TAPF (folhas. dia }{ }^{-1} \cdot \text { perfilho }^{-1} \text { ) } \\
\text { LapR (leaves.day } \text { diller }^{-1} \text { ) }\end{array}$ \\
\hline Verão (Summer) & $1,37 \mathrm{a} *$ & $3,03 \mathrm{a}$ & $0,35 \mathrm{a}$ \\
\hline Outono (Autumn) & $1,07 b$ & $3,31 \mathrm{a}$ & $0,31 \mathrm{a}$ \\
\hline CV (\%) & 13,73 & 19,64 & 24,52 \\
\hline
\end{tabular}

* Médias seguidas por letras distintas $(P<0,05)$ diferem pelo teste Tukey.

* Means followed by different letters $(P<0.05)$ differ by Tukey test. 
tura e pastejo controlam o desenvolvimento do perfilho e seu período de reprodução (Langer, 1972) (Tabela 1).

A média do número de folhas expandidas.perfilho-1, com aumento linear $(\mathrm{P}<0,05)$ em função dos dias de avaliação, variou de 3,23 a 4,45 folhas por perfilho, respectivamente, no primeiro e último dias (Figura 2). Gomide \& Gomide (2000), trabalhando com vasos contendo cultivares do gênero Panicum, verificaram a presença de três folhas verdes por perfilho para os capins mombaça e tanzânia, estando próximo dos valores médios iniciais observados neste experimento, porém para folhas expandidas.

Em geral, existe um equilíbrio na produção de folhas em um perfilho, pois no ciclo de vida de folhas sucessivas está intimamente relacionado à cessação do crescimento da folha anterior, uma vez que o aparecimento de uma nova folha e a senescência de uma folha madura ocorrem simultaneamente, o que define um número mais ou menos constante de folhas em um perfilho (Hodgson, 1990).

$\mathrm{O}$ número de folhas em expansão.perfilho ${ }^{-1}(\mathrm{NFE})$ (Figura 3) apresentou relação linear negativa $(\mathrm{P}<0,05)$, em

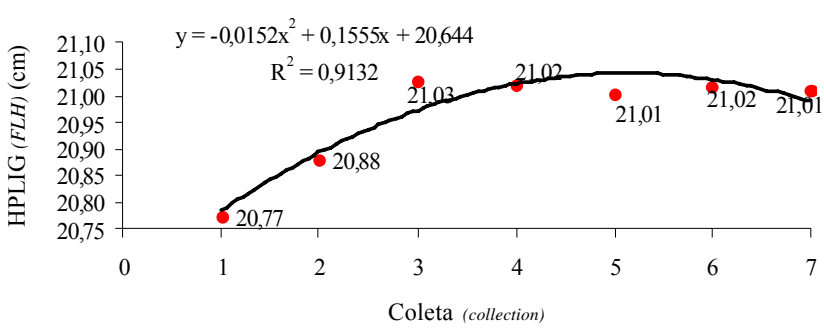

Figura 1 - Altura média da primeira lígula.perfilho-1 $(\mathrm{HPLIG}, \mathrm{cm})$ do capim-mombaça, em função dos dias de coleta, em duas fontes de fósforo.

Figure 1 - Average first-ligule height.tiller ${ }^{-1}$ ( $\left.F L H, c m\right)$ (summer x autumn) of mombaçagrass as a function of collecting date, with two phosphorus sources.

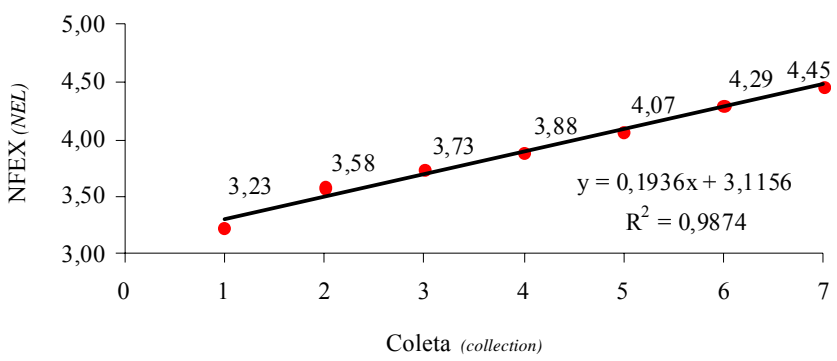

Figura 2 - Número médio de folhas expandidas.perfilho-1 (NFEX) do capim-mombaça, em função dos dias de coleta, com duas fontes de fósforo.

Figure 2 - Average number of expanded leaves.tiller-1 (NEL) of mombaçagrass as a function of collecting date with two phosphorus sources. função dos dias de avaliação. Esta queda na emissão de novas folhas pode ter sido ocasionada por algum fator fisiológico ou pelo manejo da planta. Valores superiores foram encontrados para a mesma espécie por Gomide \& Gomide (2000), trabalhando com vasos. Outro fator que pode ter contribuído para este fato é que, concomitantemente à expansão de folhas, existe o aumento do comprimento da bainha de gramíneas cespitosas, havendo maior demora em relação ao surgimento das folhas acima do cartucho (Chapman \& Lemaire, 1993).

O número total de folhas.perfilho ${ }^{-1}$ (NTF) aumentou linearmente $(\mathrm{P}<0,05)$, em função dos dias de avaliação (Figura 4)

A média do número total de folhas senescentes.perfilho- ${ }^{-1}$ (TFS) (Figura 5) aumentou $(\mathrm{P}<0,05)$ com o avanço dos dias de avaliação. Isto se explica pelo surgimento natural das folhas nos perfilhos, pois, com o avanço dos dias e o envelhecimento das mesmas, muitas senescem. Entretanto, em pastejo com lotação contínua, os animais tendem ao pastejo seletivo, despontando as folhas com inserção

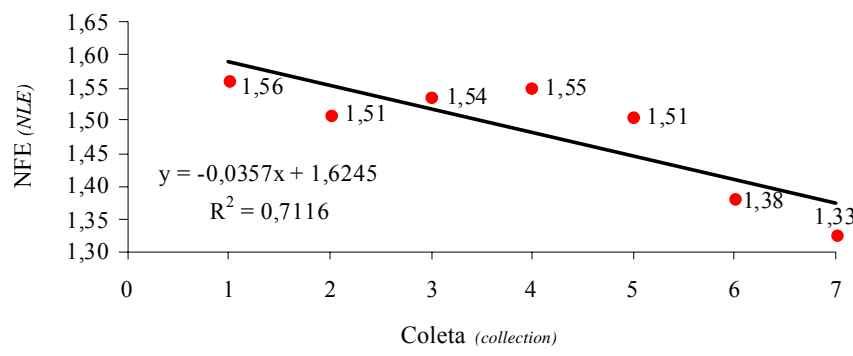

Figura 3 - Número médio de folhas em expansão.perfilho-1 (NFE) do capim-mombaça, em função dos dias de coleta, com duas fontes de fósforo.

Figure 3 - Average number of expanding leaves.tiller ${ }^{-1}$ (NLE) of mombaçagrass as a function of collecting date, with two phosphorus sources.

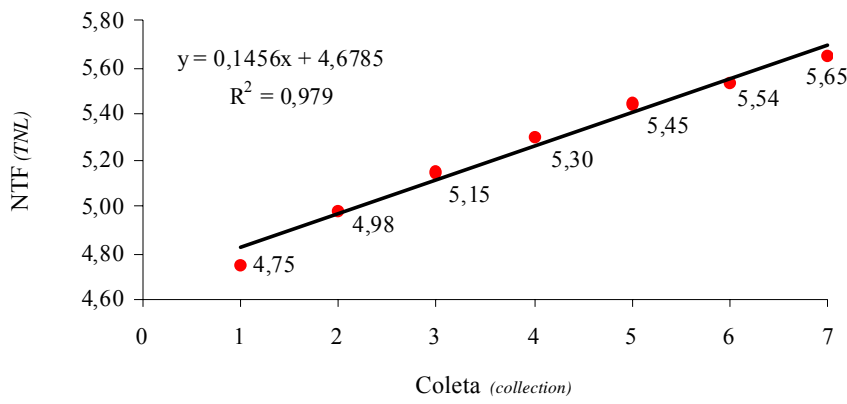

Figura 4 - Número total de folhas.perfilho-1 (NTF) do capimmombaça, em função dos dias de coleta, com duas fontes de fósforo.

Figure 4 - Total number of leaves.tiller ${ }^{-1}$ (TNL) of mombaçagrass as a function of collecting date, with two phosphorus sources. 
intermediária, mantendo intactas as folhas com inserções inferiores, onde se encontram as folhas mais velhas. Como a planta está em processo de recuperação constantemente e, talvez, no início do estádio reprodutivo, estas folhas mais velhas ocupam papel central de fonte, translocando nutrientes para a emissão de inflorescência, o alongamento do colmo ou o crescimento foliar, elevando a quantidade de folhas senescentes (Hodgson, 1994; Cecato et al., 1994).

Coelho (2001), trabalhando com ofertas de forragem e o mesmo cultivar, obteve valores semelhantes aos encontrados para TFS nesta pesquisa. Da mesma forma, para NTF e NTFV os valores ficaram bastante próximos.

Houve efeito da interação dias $\times$ época de avaliação sobre o número total de folhas vivas (NTFV), apresentando correlações lineares negativas $(\mathrm{P}<0,05)$, tanto para o verão quanto para o outono (Figura 6).

Isto, provavelmente, ocorreu em função do manejo utilizado, que manteve a altura bastante uniforme. Como os animais têm o hábito de pastejar preferencialmente folhas jovens, as mais velhas foram rejeitadas, entrando em fase de senescência, o que resultou em menor número de folhas vivas em função dos dias de avaliação. $\mathrm{O}$ fato de, no verão, a redução do NTFV ser mais acentuada também pode ser justificado pelo manejo adotado e pela maior redução de folhas totais em relação às senescentes, no outono, e pelas condições ambientais neste período, que são menos favoráveis ao crescimento.

Por outro lado, o número de folhas vivas por perfilho é uma característica genotípica bastante estável na ausência de deficiências hídricas ou nutricionais. Gomide \& Gomide (2000) encontraram 4,0 folhas vivas por perfilho no capimmombaça, valor semelhante ao encontrado nesta pesquisa.

A interação dias $\times$ época de avaliação (Figura 7) mostra que houve correlação linear $(\mathrm{P}<0,05)$ para o total de folhas senescentes (TFS).

Este resultado demonstra o contrário do ocorrido para NTFV, obtendo-se maior senescência de folhas no verão, em decorrência, provavelmente, do maior incremento de folhas senescentes no verão, que pode estar associado ao maior ritmo de crescimento das plantas nessa época. Como os animais têm o hábito de pastejar preferencialmente folhas jovens, as mais velhas são rejeitadas, entrando em fase de senescência, o que resulta em maior número de folhas senescentes, principalmente no verão. Peternelli (2003), avaliando diferentes ofertas de forragem no capim-braquiarão, verificou que maior oferta proporcionou maior taxa de senescência foliar. Como a temperatura é responsável pelo crescimento da estrutura da planta, esta também contribui para o aumento da senescência das folhas.

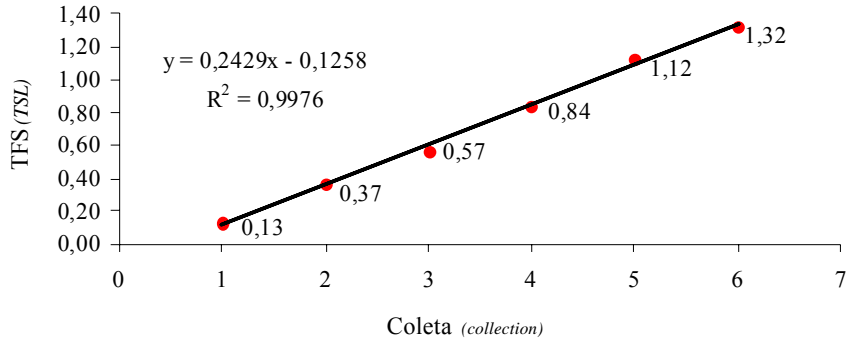

Figura 5 - Número total de folhas senescentes.perfilho-1(TFS) do capim-mombaça, em função dos dias de coleta com duas fontes de fósforo.

Figure 5 - Total number of senescent leaves.tiller ${ }^{-1}$ (TSL) of mombaçagrass as a function of collecting date, with two phosphorus sources.

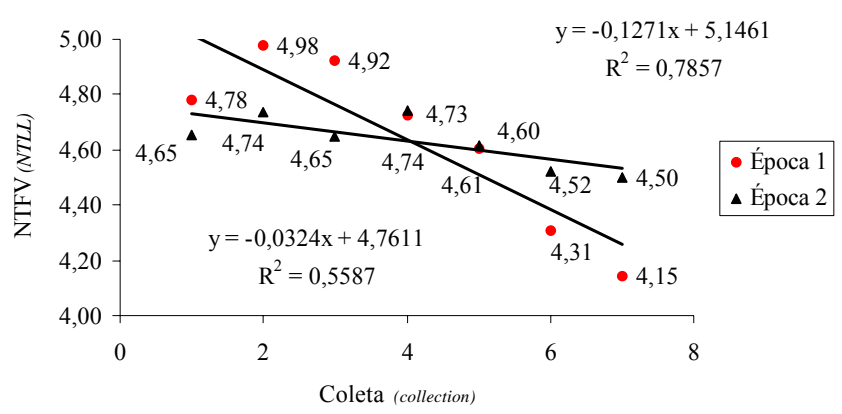

Figura 6 - Número total de folhas vivas.perfilho-1 (NTFV) no capim-mombaça, em dois períodos de avaliação. Época 1: verão; época 2: outono.

Figure 6 - Total number of alive leaves.tiller-1 (NTLL) of mombaçagrass, in two evaluation periods. Period 1: summer; period 2: autumn

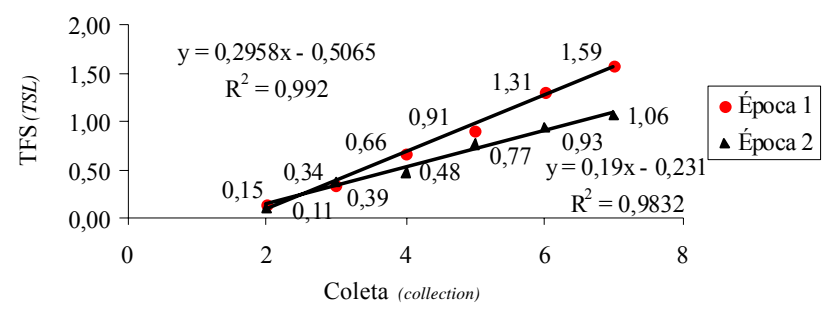

Figura 7 - Número total de folhas senescentes. perfilho-1 do capim-mombaça, em dois períodos de avaliação. Época 1: verão; época 2: outono.

Figure 7 - Total number of senescent leaves.tiller ${ }^{-1}$ (TSL), of mombaçagrass, in two evaluation periods. Period 1: summer; period 2: autumn

\section{Conclusões}

As fontes de fósforo não influenciaram as características morfogênicas do capim-mombaça, exceto o alongamento foliar, em que o tratamento SFS+SFT-fósforo solúvel promoveu maior aumento que Yoorin ${ }^{\circledR}$.

No verão, as plantas apresentaram maior crescimento dos perfílhos e de sua taxa de alongamento foliar que no outono. 


\section{Literatura Citada}

ALMEIDA, E.X.; SETELICH, E.A.; MARASCHIN, G.E. Oferta de forragem e variáveis morfogênicas em capim elefante anão cv. Mott. In: REUNIÃO ANUAL DA SOCIEDADE BRASILEIRA DE ZOOTECNIA, 34., 1997, Juiz de Fora. Anais... Juiz de Fora: Sociedade Brasileira de Zootecnia, 1997. p.240-242.

BARBOSA, M.A.A.F.; DAMASCENO, J.C.; CECATO, U. et al. Dinâmica do aparecimento, expansão e senescência de folhas em diferentes cultivares de Panicum maximum Jacq. In: REUNIÃO ANUAL DA SOCIEDADE BRASILEIRA DE ZOOTECNIA, 33., 1996, Fortaleza. Anais... Fortaleza: Sociedade Brasileira de Zootecnia, 1996. p.101-103.

CECATO, U.; FAVORETTO, V.; MALHEIROS, E.B. Freqüência de corte, níveis e formas de aplicação de nitrogênio sobre as características da rebrota do capim Aruana (Panicum maximum Jacq. cv. Aruana). Revista Unimar, v.16, n.3, p.263-276, 1994.

CHAPMAN, D.F.; LEMAIRE, G. Morphogenetic and structural determinants of regrowth after defoliation. In: INTERNATIONAL GRASSLAND CONGRESS, 17., 1993, New Zealand. Proceedings... New Zealand: s.ed., 1993. p.95-104.

COELHO, E.M. Efeito de oferta de forragem e período de ocupação em algumas características morfogênicas do capim-mombaça (Panicum maximum Jacq. cv. Mombaça). Pirassununga: Universidade de São Paulo, 2001. 55p. Dissertação (Mestrado em Zootecnia) - Universidade de São Paulo, 2001.

CORRÊA, A.R. Forrageiras: aptidão climática do estado do Paraná. In: MONTEIRO, A.L.G. et al. (Eds.) Forragicultura no Paraná. Londrina: Comissão Paranaense de Avaliação de Forrageiras, 1996. p.72-92.

CORSI, M. Effects of nitrogen rates and harvesting intervals on dry matter productivity, tillering and quality of tropical grass Panicum maximum Jacq. Ohio: Ohio State University, 1984. 125p. Thesis (PhD.) - Ohio State University, 1984.

EMPRESA BRASILEIRA DE PESQUISA AGROPECUÁRIA EMBRAPA. Sistema brasileiro de classificação de solos. Brasília: Centro Nacional de Pesquisa de Solos, 1999. 412p.

FONSECA, D.M.; GOMIDE, J.A.; ALVAREZ, V.H. et al. Absorção, utilização e níveis críticos internos de fósforo e perfilhamento em Andropogon gayanus e Panicum maximum. Revista Brasileira de Zootecnia, v.29, n.6, p.1918-1929, 2000.

FRANCO, H.C.J. Avaliação agronômica de fontes e doses de fósforo para o capim Tifton 85. Jaboticabal: Universidade Estadual Paulista, 2003. 80p. Dissertação (Mestrado em Agronomia) - Universidade Estadual Paulista, 2003.

GOMIDE, C.A.M.; GOMIDE, J.A. Morfogênese de cultivares de Panicum maximum Jacq. Revista Brasileira de Zootecnia, v.29, n.2, p.341-348, 2000 .

GOMIDE, C.A.; GOMIDE, J.A. Morfogênese e análise de crescimento de cultivares de Panicum maximum. In: REUNIÃO ANUAL DA SOCIEDADE BRASILEIRA DE ZOOTECNIA, 34., 1997, Juiz de Fora. Anais... Juiz de Fora: Sociedade Brasileira de Zootecnia, 1997. p.403-406.

GONÇALVES, A.C. Características morfogênicas e padrões de desfolhação em pastos de capim Marandu submetidos a regimes de lotação contínua. Piracicaba: Escola Superior de Agricultura Luiz de Queiroz, 2002. 124p. Dissertação (Mestrado em Zootecnia) - Escola Superior de Agricultura Luiz de Queiroz, 2002.

GRANT, S.A.; BERTHARM, G.T.; TORVELL, L. Components of regrowth in grazed and cut Lolium perene swards. Grass and Forage Science, v.36, p.155-168, 1981.

HODGSON, J. Grazing management: science into practice. London: Longman Scientific and Technical Group, 1990. 203p.

LANGER, R.H. How grasses grow. London: Edward Arnold, 1972. 60p. (Studies in biology, 34).
LEMAIRE, G.; AGNUSDEI, M. Leaf tissue turn-over and efficiency of herbage utilization. In: INTERNATIONAL SYMPOSIUM GRASSLAND ECOPHYSIOLOGY AND ECOLOGY, 1999, Curitiba. Anais... Curitiba: Universidade Federal de Curitiba, 1999. p.109-133.

LEMAIRE, G. The physiology of grass growth under grazing: tissue turnover. In: SIMPÓSIO INTERNACIONAL SOBRE PRODUÇÃO ANIMAL EM PASTEJO, 1997, Viçosa, MG. Anais... Viçosa, MG: Universidade Federal de Viçosa, 1997. p. $115-144$.

MORALES, A.S.; NABINGER, C.; MARASCHIN, G.E. et al. Efeito da disponibilidade hídrica sobre a morfogênese e a repartição de assimilados em L. corniculatus L. cv. São Gabriel. In: REUNIÃO ANUAL DA SOCIEDADE BRASILEIRA DE ZOOTECNIA, 34. 1997, Juiz de Fora. Anais... Juiz de Fora: Sociedade Brasileira de Zootecnia, 1997. p.124-126.

MOTT, G.O.; LUCAS, H.L. The design, conduct and interpretation of grazing trials on cultived and improved pastures. In: INTERNATIONAL GRASSLAND CONGRESS, 1952, Pensylvania. Proceedings... Pensylvania: State College Press, 1952. p.1380-1385.

NABINGER, C. Princípios da exploração intensiva de pastagens. In: PEIXOTO, A.M., MOURA, J.C., FARIA, V.P. (Eds.) Produção de bovinos a pasto. SIMPÓSIO SOBRE MANEJO DA PASTAGEM, 13., 1996, Piracicaba. Anais... Piracicaba: Fundação de Estudos Agrários Luiz de Queiroz, 1996.

PETERNELLI, M. Características morfogênicas e estruturais do capim-braquiarão [Brachiaria brizantha (Hochst ex A. Rich.) Stapf. cv. Marandu] sob intensidades de pastejo. Pirassununga: Universidade de São Paulo, 2003. 79p. Dissertação (Mestrado em Zootecnia) - Universidade de São Paulo. Disponível em: <http:// www.teses.usp.br>. Acesso em: 8/12/ 2003.

PONTES, L.S. Dinâmica de crescimento em pastagens de azevém anual (Lolium multiflorum Lam.) manejadas em diferentes alturas. Porto Alegre: Universidade Federal do Rio Grande do Sul, 2000. 102p. Dissertação (Mestrado em Zootecnia) - Universidade Federal do Rio Grande do Sul, 2002.

RODRIGUES, L.R.A; RODRIGUES, T.J.D. Ecofisiologia de plantas forrageiras. In: CASTRO, P.R.; FERREIRA, S.O.; YAMADA, T.V. (Eds.) Ecofisiologia da produção agrícola. Piracicaba: Associação Brasileira para Pesquisa da Potassa e Fosfato, 1987. p.203-227.

SANTOS, P.M.; BALSALOBRE, M.A.A.; CORSI, M. Uso do número de folhas por perfilho no manejo de Panicum maximum Jacq. cvs. Mombaça e Tanzânia. In: REUNIÃO ANUAL DA SOCIEDADE BRASILEIRA DE ZOOTECNIA, 36., 1999, Porto Alegre. Anais... Porto Alegre: Sociedade Brasileira de Zootecnia, 1999. p. 62

STATISTICAL ANALYSIS SYSTEM - SAS. SAS/STAT: user's guide: statistics. versão 6. 4.ed. Cary: 1993. v.2. 412p.

SKINNER, R.H.; NELSON, C.J. Elongation of the grass leaf and its relationship to the phyllochron. Crop Science, v.35, p.4-10, 1995.

WERNER, J.C. Adubação de pastagens. Nova Odessa: Instituto de Zootecnia, 1984. 49p. (Boletim Técnico, 18).

ZARROUGH, K.M.; WILSON, C.J.; SLEPER, D.A. Interrelationship between rates of leaf appearance and tillering in selected tall fescue populations. Crop Science, v.24, n.3, p.565-568, 1984 .
Recebido: 20/4/2006 Aprovado: $1 / 6 / 2007$ 